\title{
A Quadratic Optimization Model for the Consolidation of Farmland by Means of Lend-Lease Agreements
}

\author{
Andreas Brieden and Peter Gritzmann \\ brieden/gritzman@ma.tum.de \\ Zentrum Mathematik, Technische Universität München \\ D-80290 München, Germany
}

\begin{abstract}
In many regions farmers cultivate a number of small lots that are distributed over a wider area. This leads to high overhead costs and economically prohibits use of high tech machinery hence results in a non-favorable cost-structure of production. The classical form of land consolidation is typically too expensive and too rigid, whence consolidation based on lend-lease agreements has been suggested. In order to exploit the potential of this method specific mathematical optimization algorithms are needed, particularly since the underlying problem is NP-complete even in very restricted cases.

This paper introduces a quadratic optimization model and shows its practicality for some typical regions in Northern Bavaria, Germany.
\end{abstract}

\section{Introduction}

In many regions in Germany and other countries individual farmers cultivate a number of rather small lots that are distributed over a wider area. Figure 1 depicts an example from Northern Bavaria, Germany. ${ }^{1}$ On the average, today's Bavarian farmers cultivate twelve lots with an average size of 1.45 hectare $^{2}$ (ha).

Naturally, in such a situation the farmers are faced with an unnecessarily large unproductive overhead, the man power and equipment needed for reaching each individual lot. In fact, according to calculations of the State Institute of Bavaria for Agriculture (LfL) in Munich, Germany, this overhead may reach as much as about ten percent of the total net income. Further, larger machinery cannot be used profitably. The reason for such small-split farmland lies in the heritage laws combined with an increase of leased but not owned agricultural property.

In the classical form of land consolidation all lots are first combined to one large region which is subsequently partitioned into the new individual properties of the corresponding farmers. At the same time the complete infrastructure of the area is replanned. This legal change of ownership is very

${ }^{1}$ The reproduction process did not allow for colors; the original multicolor figures can be viewed under http://www-m9.ma.tum.de/dm/consolidation/OR2003

${ }^{2} 1 \mathrm{ha}=10.000 \mathrm{~m}^{2}=2,471$ acres 


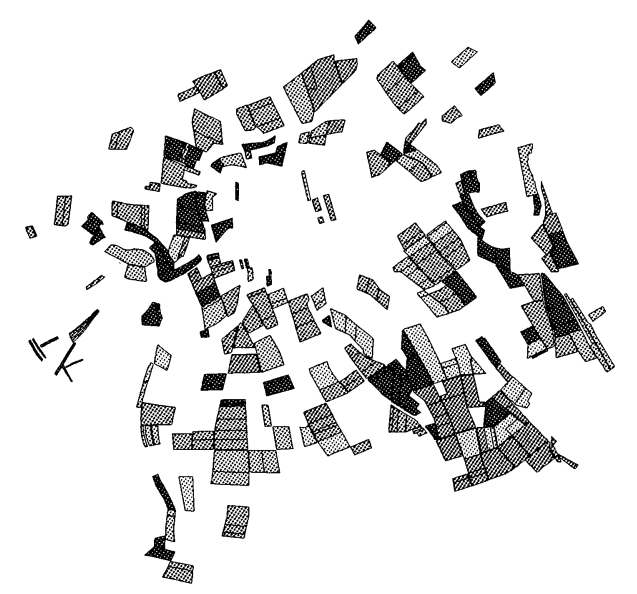

Fig. 1. Status quo distribution of the lots of individual farmers; lots depicted in the same grey value belong to the same farmer.

costly, time intense, rigid and its fairness is always up to dispute. In fact, the cost per hectare are about 2000 Euro, the duration of the procedure not rarely close to a decade, and normally each farmer is forced to participate.

Therefore the LfL suggested a lend-lease based redistribution of the $e x$ isting lots. This means that the redistribution will not result in any resizing or legal change of ownership but only in a (temporary) reassignment of utilization. Consequently, the method is easy to implement, inexpensive and very flexible. It actually works on a voluntary basis, no farmer is forced to participate. Also individual preferences can be accommodated, and updates can be performed on any time scale that is required.

In practice, the real bottleneck of this approach is that adequate techniques for the redistribution of utilization rights that take into account the quality of the soil, the (real or potential) European Union subsidy benefits and many other relevant factors are not at hand of the farmers or the experts of the ministry. In fact, even extremely simple seeming cases can be shown to be NP-complete, see [4].

The purpose of this note is to outline a new quadratic optimization model for the lend-lease based consolidation of farming. A more detailed description and analyses will be given in [4]. In Section 2 we present the core model and Section 3 contains computational results for two regions in Northern Bavaria.

\section{Mathematical Model}

Let the given farmland be split into - say $-l^{*}$ lots $L_{1}, \ldots, L_{l^{*}}$, and let the function $\omega:\left\{L_{1}, \ldots, L_{l^{*}}\right\} \rightarrow[0, \infty[$ associate with each lot its size (or soil quality or subsidy potential or any other kind of measure for its quality). Now, the lots are cultivated by - say $-f^{*}$ different farmers $F_{1}, \ldots, F_{f^{*}}$, i.e., 